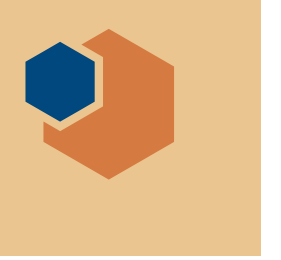

\section{US government shows favor for National Quantum Initiative}

$\mathrm{W}^{\mathrm{i}}$ ith strong bipartisan support, proposed legislation to create a National Quantum Initiative (NQI) has made steady progress moving through the US Congress over the summer. If the momentum holds - and there is little reason to think otherwise - a final bill for signature into law by the president is expected to happen this fall.

Materials researchers, along with scientists in many other relevant disciplines, say the National Quantum Initiative Act will supercharge efforts to keep US scientists at the leading edge of quantum research. Development of new quantum materials is fundamental to the advancement of quantum technologies such as quantum computing, quantum sensors, and telecommunications systems (see
"Quantum materials: Where many paths meet," MRS Bulletin, October 2017).

The money behind the NQI will need to come in at around $\$ 80$ million to $\$ 120$ million, says Idaho National Laboratory materials researcher Jeffery Aguiar, who works in the subfield of condensed-matter physics. "This is what it will take to be competitive internationally," he says.

The federal government's interest in this initiative stems from the National Science and Technology Council Report in 2016 that summarizes some of the promises of quantum science for the country. Pointing to the interdisciplinary nature of the field as well as the likelihood for considerable economic advantages, the report says, "A coherent, all-of-government approach will facilitate advancement [in this field]."

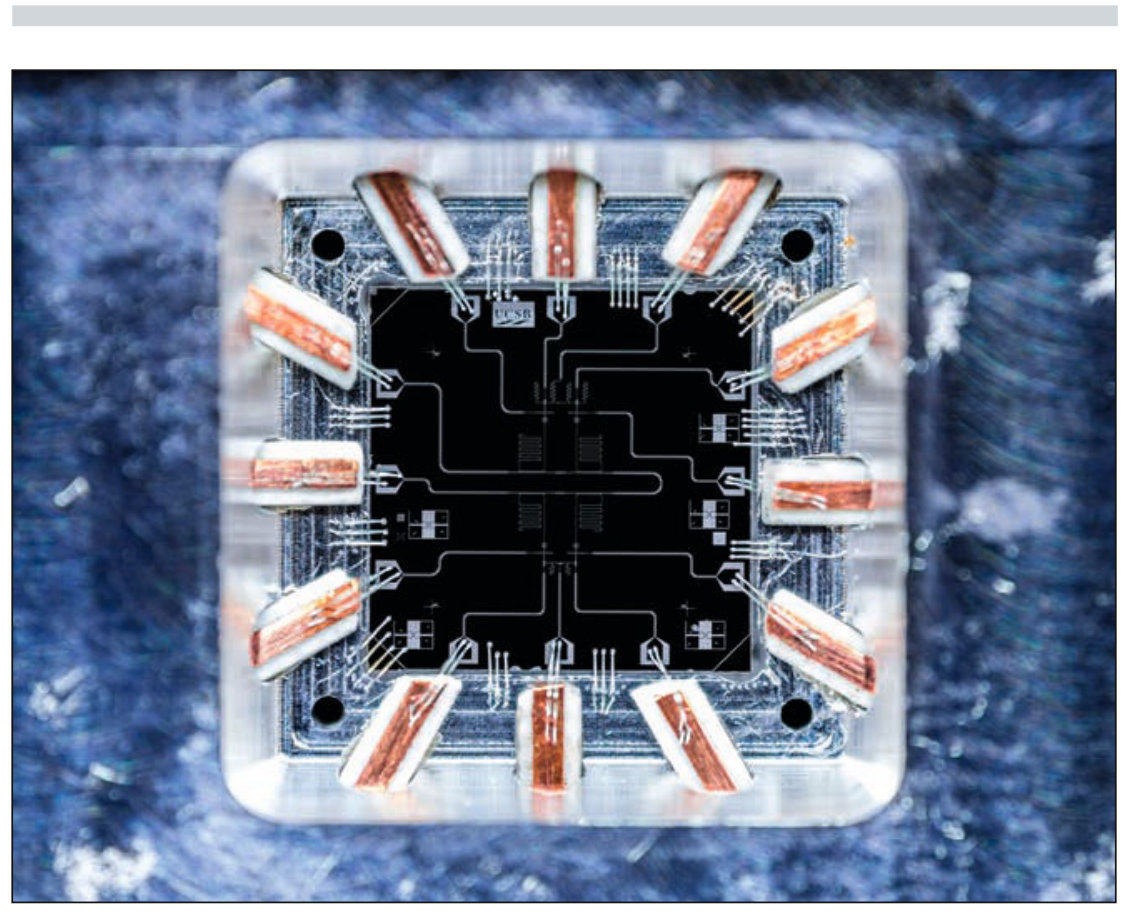

A superconducting qubit chip. The size of the chip is about $6 \mathrm{~mm}$ by $6 \mathrm{~mm}$. The wafer was made by depositing $200 \mathrm{~nm}$ of aluminum on a sapphire substrate, followed by a multilayer lithography process, to nanofabricate various elements of the quantum processor. Credit: Michael T. Fang, Martinis Group, UC Santa Barbara.
The National Photonics Initiative, which has been lobbying Congress for this legislation since last year, says that the Act, if it became law, would "establish a comprehensive, coordinated national policy to encourage quantum research and technology and develop a workforce capable of transforming that work into real world applications." The National Photonics Initiative is a broadbased alliance of industry, academia, and government entities.

In June, the House Committee on Science, Space, and Technology unanimously passed H.R. 6227, the National Quantum Initiative Act, and a companion bill in the Senate, S. 3143, was advanced by the Senate Committee on Commerce, Science, and Transportation.

"It's going to happen," Aguiar says, adding that the implications for national security alone make the case for the United States to take the lead in funding quantum technologies. He says he met recently with US House Representative Joe Barton (R-Texas), vice chair of the House Energy and Commerce Committee, who wanted to know why current funding was not enough.

Aguiar says he explained to Barton that countries like China and India are investing heavily in quantum science research and that the work involves much more than just quantum information/quantum computing. In a press statement regarding H.R. 6227, House Science Committee Chair Lamar Smith (R-Texas), said, "As other nations are rapidly developing their own quantum programs, the US faces the risk of falling behind."

While pointing to US competitiveness, the National Science and Technology Council Report also describes the need for US researchers to collaborate across national borders. The report identifies several quantum research initiatives in Europe. "With the increase in activity abroad," the report says, "international collaboration is becoming more common."

The House Science Committee Ranking Member Eddie Bernice Johnson (D-Texas) said in her press statement last June, "Advancements in the field of quantum information science promise to revolutionize the way we solve society's most pressing problems." 
There will be numerous technological advances and other benefits to the country from a sustained initiative, Aguiar agrees.

Aguiar gives as an example of his own scientific research in cryo-TEM, or cryogenic tansmission electron microscopy. This extremely low-temperature method allows researchers to work at the atomistic level, and to examine and manipulate phenomena such as electron spin states that are for quantum computing and other quantum technologies.

Working at very low temperatures adds to cost and equipment size, Aguiar says, and so researchers want to find ways to do this work at the atomic level at higher temperatures. Many other physics and materials science problems will benefit from these breakthroughs, he says.

Of quantum computers that exist today, Aguiar says, "We have them; they are really large and require a lot of cooling. We want to scale that technology down."

The NQI Act will also provide the funds needed to upgrade some of the country's major scientific user facilities, for example, the beamlines at Argonne National Laboratory that are used to study materials and problems across a range of disciplines. Upgraded scientific user facilities also mean jobs, Aguiar says. "We want really skilled technicians who can work with researchers, perhaps in addition to their own research. There would be hiring at all levels."

The NQI Act will enhance existing federal programs to support quantum research, such as the Quantum Leap program at the National Science Foundation (NSF), says Fil Bartoli, Division Director for the Division of Electrical, Communications and Cyber Systems. Quantum
Leap was one of NSF's 10 Big Ideas for Future Investment identified by NSF in 2016. It is a $\$ 30$ million per year, multipronged effort to advance fundamental understanding of quantum phenomena, materials, communications, and systems, Bartoli says. The agency plans to announce new funding opportunities under the program this year.

Materials science will be a "veritable treasure mine," Bartoli says. "The materials division at NSF is heavily involved."

"A lot of materials questions will have to be answered," Bartoli says, that will bring together research on superconducting materials, trapped ion technologies, and neutral ion vacancies, for example.

As Quantum Leap and the NQI Act get rolling, "there are going to be quite a few opportunities to have a big impact on society," Bartoli says.

William G. Schulz
CSIRO looks to space industry to support "lunar" challenge

www.csiro.au

$\mathrm{T}_{\mathrm{s}}$ he latest industry roadmap published by CSIRO, Australia's national science agency, encourages the growing Australian space sector to join with international partners to provide technological expertise to help to establish a human base on the Moon. According to Megan Clark, head of the Australian Space Agency, the agency is mandated to grow the size of the domestic space industry to $\$ 12$ billion by 2030 .

According to CSIRO, meeting the "lunar" challenge would involve building capabilities in autonomous robotic systems, in situ resource utilization, habitat and life support, and power and propulsion. Deep-space exploration missions are hostile environments for humans, so developments in machine learning, artificial intelligence, and robotics are essential to gather data and supporting analytics. To support habitat and life on the Moon, the development of innovative systems will be needed to provide food, medicine, shelter, and waste management.

Use of local resources at the exploration destination may require mapping and prospecting, processing of new minerals and materials, and additive manufacturing capabilities, according to the roadmap. Furthermore, technology solutions suitable for in situ power generation, energy harvesting and storage, engine and fuel options for rockets, and in-space propulsion will be needed.

An international coordination group already exists with the aim of expanding human exploration and presence in low
Earth orbit, and on the Moon and Mars, over the next two decades. Australian space sector support for the lunar challenge would be an opportunity to grow these existing relationships with global partners, including international space agencies.

Launched in September by the Minister for Industry, Science and Technology, Karen Andrews, at the 18th Australian Space Research Conference, the report"Space: A Roadmap for Unlocking Future Growth Opportunities for Australia"highlights Australia's unique strengths and geographic advantages to increase the country's share of the international space sector.

The new roadmap was developed by CSIRO Futures, the strategic advisory arm of CSIRO, following extensive industry consultation with nearly 150 business, government, and technology representatives.

Wewelcome comments and feedback on these articles via email to Bulletin@mrs.org.

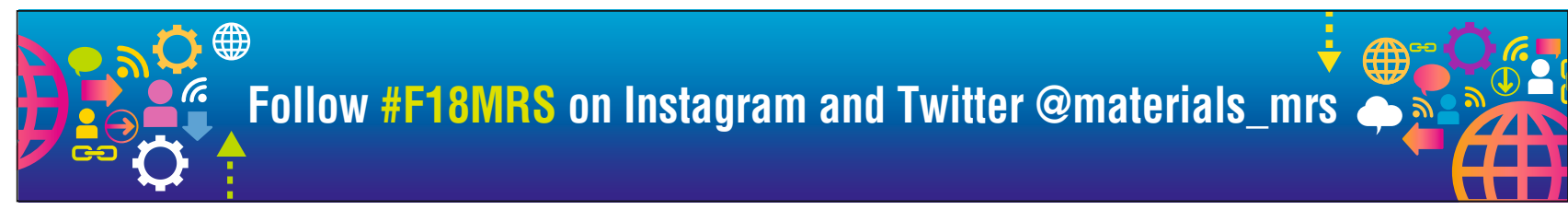

